\title{
SISTEM PENILAIAN PENGUJI PADA UJIAN KENAIKAN TINGKAT SABUK TAEKWONDO BERBASIS LARAVEL FRAMEWORK DI KOTA/KABUPATEN
}

\author{
Qurotul Aini ${ }^{1}$, Untung Rahardja ${ }^{2}$, Aditiya Lityanian Al Nasir ${ }^{3}$ \\ ${ }^{1,3}$ Program Studi Sistem Informasi Universitas Raharja \\ ${ }^{2}$ Program Studi Magister Teknik Informatika Universitas Raharja \\ Jl. Jendral Sudirman No. 40 Modernland Tangerang \\ Iaini@raharja.info, ${ }^{2}$ untung@raharja.info, ${ }^{3}$ aditya.lityanian@raharja.info
}

\begin{abstract}
Abstrak-Pengembangan sistem adalah suatu usaha untuk ekspansi kualitas sistem sehingga terus berubah menjadi lebih baik. Pengurus cabang (pengcab) Taekwondo Indonesia merupakan susunan kepengurusan Taekwondo di Kota/Kabupaten yang belum memiliki suatu sistem dalam mendukung kegiatan administrasi organisasi. Pada Pengcab Taekwondo Indonesia terdapat Ujian Kenaikan Tingkat (UKT) sabuk yang merupakan syarat bagi Taekwondoin sebagai media untuk menguji kualitas dan kelayakan dengan cara memenuhi poin penilaian yang ditentukan dan dinilai oleh penguji. Penilaian Penguji amat lah penting untuk mempermudah penguji dalam memberikan penilaian yang ditujukan kepada Taekwondoin yang sedang mengikuti UKT sabuk. Namun, belum adanya sistem penilaian penguji saat ini sehingga memiliki permasalahan yaitu dimana penguji mengisi penilaian secara tertulis menggunakan lembar penguji. Dari pokok masalah tersebut maka diperlukan peningkatan pada penilaian penguji agar dapat diakses secara online pada UKT sabuk Taekwondo agar menjadi lebih terstruktur, terarah, efektif serta jauh lebih efisien dan dapat diakses secara online. Pada pengembangan sistem penilaian Penguji ini menggunakan salah satu Framework PHP yaitu Laravel Framework.
\end{abstract}

Keywords - Ujian Kenaikan Tingkat, Penilaian Penguji, Taekwondo

Abstract-System development is an attempt to expand the quality of the system so that it continues to change for the better. The branch manager (pengcab) of Taekwondo Indonesia is a Taekwondo management structure in the City / Regency that does not yet have a system to support the organization's administrative activities. In Pengcab Taekwondo Indonesia, there is a Belt Increase Test (UKT) which is a requirement for Taekwondoin as a medium to test quality and feasibility by fulfilling the assessment points determined and assessed by the examiner. The examiner's assessment is very important to make it easier for the examiners to provide an assessment aimed at Taekwondoin who are following the belt UKT. However, there is no current assessment system for examiners so that it has problems, namely where the examiners fill in the assessment in writing using the test sheet. From the point of the problem, it is necessary to increase the assessment of examiners so that they can be accessed online at the Taekwondo belt UKT to be more structured, directed, effective and far more efficient and can be accessed online. On the development of the scoring system, the examiner uses one of the PHP frameworks, Laravel Framework.

Keywords — Test for Increase in Level, Test for Assessment, Taekwondo

\section{PENDAHULUAN}

Informasi adalah kunci keberhasilan dalam berkomunikasi.[1] Sistem Penilaian Pengujian sangat penting dalam proses menjalankan tugas akhir uji coba.[2] Ujian Kenaikan Tingkat (UKT) sabuk adalah suatu kegiatan dengan tujuan menguji serta mengevaluasi kemampuan Taekwondoin untuk naik ke tingkat sabuk berikutnya, Taekwondoin mempresentasikan gerakan teknik tangan, teknik kaki, dan rangkaian gerakan sesuai poin penilaian tersebut pada Penguji. Pengertian Penilaian adalah proses pengumpulan serta pengolahan informasi yang memiliki makna dalam pengambilan keputusan dan penentuan kualitas Taekwondoin. Penilaian juga bisa menjadi acuan untuk mendapatkan informasi tentang Taekwondoin seberapa baik hasil latihan maupun yang sudah diraih oleh Taekwondoin. Hasil penilaian bisa berupa nilai kuantitatif (angka) dan nilai kualitatif (pernyataan naratif dalam kata-kata). Penilaian adalah sikap dan persepsi positif terhadap pengetahuan, pemerolehan dan pengintegrasian pengetahuan, perluasan dan pendalaman pengetahuan, penggunaan pengetahuan secara bermakna, dan kebiasaan berpikir produktif.[3]

Mutu serta pengetahuan dunia beladiri Taekwondo berikut dengan elemen nya saat ini 
tentunya tidak terlepas dari penggunaan teknologi komputer sebagai salah satu penghubung yang banyak memberikan manfaat. Teknologi pun saat ini tidak hanya menjangkau perkantoran, instansi-instansi masyarakat seperti Universitas. Tetapi, sampai ke dunia beladiri Taekwondo. Akan tetapi pemenuhan kebutuhan atas informasi pada saat ini tidak lepas dari penggunaan dan pemanfaatan komputer dengan semaksimal mungkin. Dibandingkan dengan tidak adanya teknologi, kurang nya pemahaman atas teknologi komputer menghambat akses atau jalannya suatu olahraga beladiri ke dunia luar.

Saat ini pada Pengcab Taekwondo Indonesia Kabupaten Tangerang masih menggunakan sistem penilaian penguji UKT sabuk yang masih manual dimana setelah penguji memberikan hasil penilaian ujian, selanjutnya salah satu pengurus Pengcab Taekwondo Indonesia Kabupaten Tangerang bidang UKT menginput nilai ke dalam excel. Tetapi pada sistem yang berjalan saat ini memiliki beberapa kekurangan dimana sistem penilaian UKT sabuk Taekwondoin masih konvensional dan saat ini ingin diterapkan agar bisa diakses secara online. Sistem penilaian UKT sabuk saat ini masih menginput secara manual menggunakan form lembar penguji.

Dengan permasalahan tersebut, dibutuhkan suatu sistem yaitu Penilaian UKT sabuk yang bisa di akses secara online. Tujuan dibuat nya sistem penilaian UKT sabuk adalah mengoptimalkan penilaian UKT, menghemat waktu dan untuk mempermudah penguji UKT agar lebih efektif dan efisien. Penelitian ini dilakukan untuk meningkatkan kualitas serta mutu dan menganalisa masalah-masalah apa saja yang ada pada sistem Penilaian Penguji UKT sabuk yang sedang berjalan saat ini dan melakukan pembuatan sistem yang memudahkan penguji UKT dalam memberikan penilaian.

\section{METODE PENELITIAN}

Metode studi pustaka merupakan teknik pengumpulan data maupun informasi dengan menelaah dari berbagai sumber seperti buku, jurnal, karya ilmiah dan lain-lain.[4] Tinjauan pustaka adalah sebagai penelusuran terhadap literature yang telah ada sebelumnya dan berkaitan dengan penelitian ini.[5] Berikut ini 6 (enam) referensi studi pustaka (literature review), yaitu:

1. Penelitian dilakukan oleh Indri Handayani, dkk.(2019), yang berjudul "Sistem Penilaian Penguji pada PESSTA+ S2 berbasis YII Framework Sebagai Media Penginputan Nilai Sidang Tesis di Perguruan Tinggi" Penelitian ini membahas tentang sebuah sistem Penilaian Sidang Tesis Akhir yang bisa diakses secara online juga bisa di akses pada sistem PESSTA+. Tujuan dibuatnya sistem ini adalah untuk mengoptimalkan penilaian sidang, memudahkan penguji sidang, efektif, serta efisien.[6]

2. Penelitian dilakukan oleh Diah Aryani, dkk. (2017), yang berjudul "Perancangan $\mathrm{PEN}+$ menggunakan metode YII Framework pada Perguruan Tinggi Raharja "Penelitian ini mengulas tentang Website PEN+ yang merupakan sistem metode penilaian pada Perguruan Tinggi Raharja yang bisa diakses secara online dan terkomputerisasi dimana mempermudah dosen untuk melakukan penginputan atau pengoreksian nilai UTS, UAS, dan TM juga hal gamifikasi dosen dan kecepatan informasi yang didapat oleh mahasiswa.[7]

3. Penelitian dilakukan oleh Erick Febriyanto, dkk. (2018), yang berjudul "Sistem Penilaian Pembimbing pada PESSTA+ S2 Berbasis YII Framework Sebagai Media Penginputan Nilai Mahasiswa Pasca Sarjana di Perguruan Tinggi Raharja” Penerapan ini mengulas tentang PESSTA + (Penilaian Sidang Skripsi dan Tugas Akhir Plus) merupakan sebuah sistem validasi Penilaian Objektif Sidang yang bisa di akses secara pribadi dan online yang ditujukan untuk mempermudah mahasiswa dalam memenuhi 10 Penilaian Objektif pada saat Sidang Tesis yang dapat mempermudah pembimbing dalam menginput Penilaian Pembimbing juga memberikan informasi seputar Penilaian Pembimbing yang bisa diakses kapan saja dan dimana saja.[8]

4. Penelitian ini dilakukan oleh Erick Febriyanto, dkk. (2018), yang berjudul “Aplikasi Sistem Penilaian Penguji Berbasis YII Framework Sebagai Media Input Nilai Mahasiswa Sidang Tugas Akhir dan Skripsi Pada Perguruan Tinggi" penelitian ini mengulas tentang pembuatan suatu sistem penilaian penguji yang dapat diakses secara online dan terhubung dengan sistem PESSTA+ sehingga menjadi lebih tersusun, terorganisir, efektif dan efisien.[9]

5. Penelitian ini dilakukan oleh Erlianti Putri, dkk. (2017), yang berjudul “Aplikasi Pengolahan Data Anggota dan Informasi Kegiatan Taekwondo Indonesia Kota Cimahi Berbasis Web" penelitian ini mengulas tentang Sistem Informasi Pendataan Anggota Taekwondo Indonesia Kota Cimahi berbasis web dengan menggunakan metode Waterfall yang bertujuan untuk mempermudah pendaftaran peserta Ujian Kenaikan Tingkat.[10]

6. Penelitian ini dilakukan oleh Santoso Pamungkas, dkk. (2018), yang berjudul "Sistem Pendukung Keputusan Penilaian Ujian Kenaikan Tingkat Taekwondo Menggunakan Metode Weighted 
Product WP-FMADM" Penelitian ini mengusungkan sebuah sistem pendukung keputusan dengan menggunakan metode Fuzzy Multiple Attribute Decision Making (MADM) dengan tujuan mencari penjumlahan terbobot dari rating kinerja pada setiap opsi dari semua atribut dimana yang berhak naik tingkat ujian sabuk adalah yang memenuhi kriteria kenaikan tingkat.[11]

\section{HASIL DAN PEMBAHASAN}

\section{A. Analisa Permasalahan}

Dengan adanya kemajuan teknologi yang amat pesat, siapapun bisa dengan mudahnya mendapatkan sebuah informasi dari berbagai sumber, termasuk melalui media online. Dikarenakan besarnya kebutuhan akan informasi, saat ini banyak situs website resmi di bidang perdagangan, kelembagaan, di bidang pendidikan maupun di dalam bidang olahraga, dalam bidang olahraga beladiri, banyak situs website resmi yang memberikan informasi seputar olahraga beladiri yang dapat diakses oleh public. Namun, belum adanya sistem yang mendukung untuk kegiatan Ujian Kenaikan Tingkat secara online. Pada sistem penilaian penguji yang berjalan di Pengcab Taekwondo Indonesia Kabupaten Tangerang masih menggunakan sistem manual yang masih memiliki kekurangan yang perlu dianalisa dan dikembangkan menjadi sistem yang lebih bermanfaat bagi penguji UKT sabuk dan bisa diakses secara online.

\section{B. Use Case Diagram Sistem Yang Berjalan}

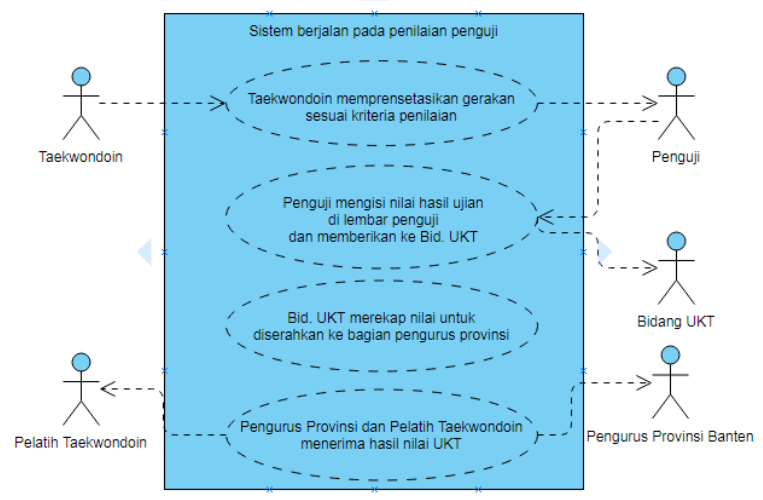

Gbr 1. Use Case Diagram Alur yang Berjalan

Berdasarkan pada gambar Use Case Diagram yang ada diatas, Dapat dijelaskan secara berikut Taekwondoin mempresentasikan gerakan yang diuji dan terdapat 4 (Empat) actor yaitu Taekwondoin, pelatih Taekwondoin, pengurus provinsi dan Penguji. Setelah Taekwondoin selesai presentasi gerakan yang diuji dan tanya jawab. Penguji memberikan Taekwondoin nilai UKT setelah selesai memberikan nilai Penguji memberikan hasil nilai ke Bid. UKT dan Bid. UKT merekap nilai setelah itu Pengurus provinsi
Banten dan Pelatih Taekwondoin mengambil hasil penilaian ke Bid. UKT.

\section{Pemecahan Masalah dan Implementasi}

Setelah mengamati dan meneliti dari permasalahan tersebut terdapat beberapa alternatif pemecahan masalah yaitu dengan membuat sistem penilaian penguji di Pengcab Taekwondo Indonesia Kab. Tangerang untuk memudahkan penguji UKT maupun administrasi dokumen ke Pengurus Provinsi untuk memperoleh informasi yang berkaitan dengan sistem Ujian Kenaikan Tingkat sabuk dan bisa mendapatkan informasi lebih efektif dan efisien ini untuk mempermudah proses penilaian Ujian Kenaikan Tingkat bagi Taekwondoin Kabupaten Tangerang. Situs web adalah halaman web yang dapat digunakan menggunakan koneksi Internet.[12]

Agar menuntaskan permasalahan yang ada diatas, maka terdapat pemecahan masalah yaitu maka diperlukannya suatu sistem yang memudahkan penguji untuk menginput Penilaian Penguji dan mendapatkan informasi seputar Penilaian Penguji yang dapat diakses dimanapun dan kapanpun secara online serta lebih efektif dan efisien. Dalam hal ini menggunakan Framework PHP yang disebut Laravel. Tujuan penggunaan Laravel untuk adalah karena Laravel itu Composed Powered, dibekali dengan command line tools bernama "Artisan" yang dapat membantu melakukan database migration, database seeding, tail, dan lain-lain, serta Beautiful Template Engine dimana sangat mempermudah dalam pembuatan syntax.

Hasil penelitian ini akan menunjukkan bahwa [13] dengan diimplementasikan nya Sistem Penilaian Penguji ini mempermudah penguji dalam proses penginputan nilai, administrasi dokumen ke bagian Pengurus Provinsi, paperless, efektif, dan efisien.

\section{Listing Program}

Listing Program berikut adalah proses login Penilaian Penguji menggunakan prototype agar dapat mengakses sumber daya hanya dengan menggunakan satu akun pengguna saja.[14] Pengguna dengan cukup melakukan proses autentikasi hanya sekali untuk mendapatkan izin akses terhadap layanan yang disediakan. Tujuan dari perancangan aplikasi ini adalah untuk dapat [15] mempermudah penguji ujian Kenaikan Tingkat dalam menilai Taekwondoin ketika Ujian Kenaikan Tingkat.

Berikut adalah listing program dari sistem Penilaian Penguji: 


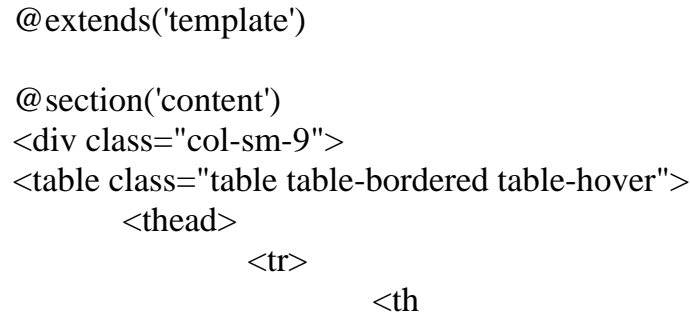
target="\#myModal" type="button" class="btn btnsuccess" $>$ Tambah $</$ button $></$ th $>$

$$
</ \text { tr }>
$$$$
<\operatorname{tr}>
$$

$<$ th $>$ No.Reg $</$ th $>$ $<$ th $>$ Nama

Taekwondoin $</$ th $>$

Movement $</$ th $>$

$<$ th $>$ Basic
Tangan $</$ th $>$
(Poomsae) $</$ th $>$

$$
<\text { th>Teknik }
$$
$<$ th $>$ Teknik Kaki</th $>$
$<$ th $>$ Fight $/$ Kyourugi $</$ th $>$
$<$ th $>$ Kyukpa $</$ th $>$ $<$ th $>$ Total $</$ th $>$ $<$ th $>$ Action $</$ th $>$

$$
\begin{aligned}
& </ \text { thead }> \\
& <\text { tbody }>
\end{aligned}
$$$$
\text { @ foreach(\$taekwondoin }
$$
$<$ th $>$ Rangkaian Jurus

\$data):?>

$$
<\operatorname{tr}>
$$$$
<\text { td }>\{\{\text { data- }>\text { noreg }\}\}</ \text { td }>
$$$$
<\mathrm{td}>\{\{\text { \$data- }
$$

>namatkd $\}\}\}</$ td $>$

$>$ teknik_tangan $\}\}</$ td $>$

$$
\begin{aligned}
& <\mathrm{td}>\{\{\$ \text { data- }>\text { bm }\}\}</ \text { td }> \\
& <\mathrm{td}>\{\{\text { d data- }
\end{aligned}
$$

$>$ teknik_kaki $\}\}</$ td $>$

$>$ teknik_kaki $\}\}</$ td $>$ $<\mathrm{td}>\{\{\$$ data$<\mathrm{td}>\{\{$ data-

$>$ poomsae $\}\}</$ dd $>$

$>$ kyourugi $\}$ </td $>$

$$
<\text { td }>\{\{\$ \text { data- }
$$

$$
<\mathrm{td}>\{\{\text { data- }
$$

$>$ kyukpa $\}\}</$ dd $>$

$$
<\mathrm{td}>\{\{\text { data- }
$$

$<$ td $>\{\{$ data- $>$ total $\}\}</$ td $>$ $\langle\mathrm{td}\rangle\langle$ button type="button" datatoggle="modal" data-target="\#myModal" class="btn btn-warning" id="edit_nilai" onclick="edit('\{ \{URL::route('taekwondoin.edit',\$ data->noreg $\left.\}\}^{\prime}\right) ; " \quad$ data-toggle="modal" datatarget="\#myModalUpdate" > Tambah/Edit Nilai $</$ button $><$ br $>$

\section{<button type="button"}

class="btn btn-success" onclick="myFunction()" style="margin-left:10px" $>$ Submit $</$ button $></$ td $>$

$$
\begin{aligned}
& \quad</ \text { tr }> \\
& \text { @ endforeach } \\
& </ \text { tbody }>
\end{aligned}
$$

$</$ table $>$

Gbr 2. Script Tampilan Penilaian Penguji

Gambar 2 merupakan listing program untuk tampilan page Penilaian Penguji yang terdapat pada sistem Penilaian Penguji UKT.

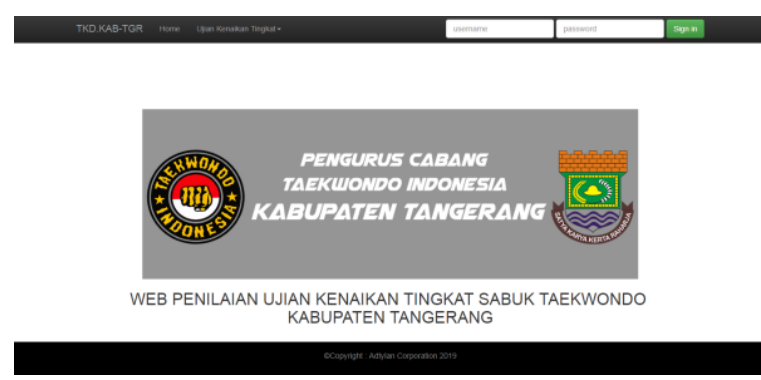

Gbr 3. Homepage Website Sistem Penilaian Penguji (Prototype)

Gambar 3 adalah tampilan homepage awal pada website Sistem Penilaian Penguji UKT Sabuk yang masih dalam bentuk prototype oleh Pengcab Taekwondo Indonesia Kabupaten Tangerang yang dapat memberikan informasi seputar hasil penilaian penguji atau ujian yang sudah dilalui sebelumnya dan konsep desain yang bisa diakses secara online. Karena, pada sistem penilaian penguji yang berjalan saat ini di Pengcab Taekwondo Indonesia Kabupaten Tangerang masih menggunakan lembar penguji dimana akan diterapkannya penilaian penguji di UKT guna bisa diakses secara online. Oleh sebab itu dibuatlah sistem dan fitur mengenai sistem penilaian Penguji pada Ujian Kenaikan Tingkat sabuk Taekwondo.

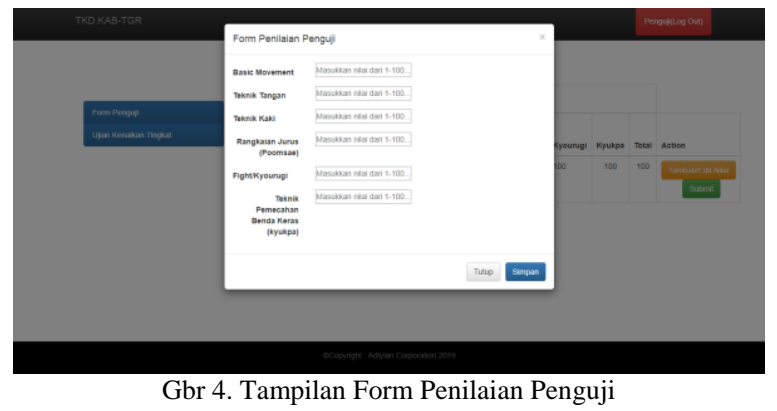

Gambar 4 adalah tampilan untuk form Penilaian Penguji Ujian Kenaikan Tingkat dimana penilaian ini sama dengan komponen penilaian pada lembar penguji. Terdapat 5 komponen yaitu basic movement, gerakan teknik tangan, gerakan teknik kaki, rangkaian 
gerakan jurus (poomsae), fight/kyourugi, dan teknik pemecahan benda keras (kyukpa) yang masingmasing komponen memiliki jumlah nilai yang berbeda .

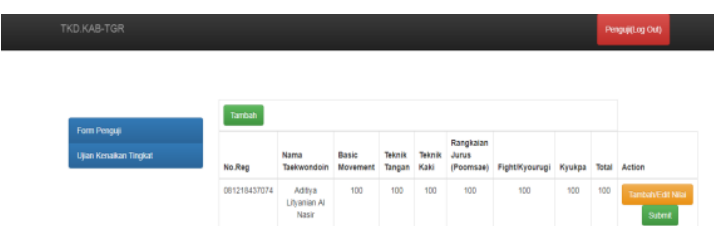

Gbr 5. Tampilan Penilaian Penguji

Gambar diatas adalah tampilan akhir ketika penguji sudah melakukan penilaian Ujian Kenaikan Tingkat dimana selanjutnya penguji bisa memfinalisasi hasil ujian tersebut untuk mengakhirinya. Apabila UKT sudah dilakukan finalisasi yang berarti menandakan bahwa UKT sudah selesai dan tidak bisa dilakukan perubahan atas nilai tersebut.

\section{PENUTUP}

Berdasarkan pengamatan yang telah dikerjakan dan telah sesuai dengan apa yang ingin divisualisasikan, dapat diambil kesimpulan yaitu dengan adanya sistem Penilaian Penguji UKT pada Pengcab Taekwondo Indonesia Kabupaten Tangerang sangat memudahkan penguji UKT dalam melakukan penilaian ujian. Dimana sistem dapat diakses dimanapun dan kapanpun secara online. Sangat memudahkan Penguji hanya perlu mengakses website sistem penilaian Penguji UKT dan menilai performa taekwondoin tanpa perlu menulis lagi di lembar penguji dan paperless .

\section{REFERENSI}

[1] Nurhaeni, T., Karts, K., \& Hardini, M. (2019). Viewboard Effectiveness on Raharja Internet Cafe Website as Sales Information Submission Media. Aptisi Transactions On Technopreneurship (ATT), 1(1), 20-26.

[2] Zarlis, M., Harahap, E., \& Husna, L. (2019). Test Appraisal System Application Based on YII Framework as Media Input Student Value Final Project and Thesis Session at Higher Education. Aptisi Transactions On Technopreneurship (ATT), 1(1), 73-81.

[3] Suastra, IW., \& Ristiati, NP. (2016). Permasalahan Guru Dalam Merancang Dan Mengimplementasikan Penilaian Otentik Dalam Pembelajaran Sains di SMP Dan SMA. Proceeding SENARI, 4.

[4] Aini, Q., Rahardja, U., Arribathi, A. H., \& Santoso, N. P. L. (2019). Penerapan Cloud Accounting dalam Menunjang Efektivitas Laporan Neraca pada Perguruan Tinggi. CESS (Journal of Computer Engineering, Science and System), 4(1), 60-64.

[5] Mahfud, M. (2016). Tinjauan hukum Islam terhadap praktek arisan sistem iuran berkembang (studi kasus di Desa Mrisen
Kec. Wonosalam Kab. Demak) (Doctoral dissertation, UIN Walisongo).

[6] Handayani, I., Yulianto., \& Khumaida, FA. (2019). Sistem Penilaian Penguji Pada PESSTA+ S2 Berbasis YII Framework Sebagai Media Penginputan Nilai Sidang Tesis di Perguruan Tinggi. SENSI Journal (Strategic of Education in Information System Journal), 5(1), 63-72.

[7] Aryani, D., Aini, Q., \& Novelia, T. (2017). Perancangan PEN+ Menggunakan Metode YII Framework pada Perguruan Tinggi Raharja. SENSI Journal (Strategic of Education in Information System Journal), 3, 48-63.

[8] Febriyanto, E., Handayani, I., \& Bachri, EW. (2018). Sistem Penilaian Pembimbing pada PESSTA+ S2 Berbasis YII Framework Sebagai Media Penginputan Nilai Mahasiswa Pasca Sarjana di Perguruan Tinggi Raharja. SATIN (Sains dan Teknologi Informasi, 4(2),17-23.

[9] Febriyanto, E., Handayani, I., \& Suprayogi, D. (2019).Aplikasi Sistem Penilaian Penguji Berbasis YII Framework Sebagai Media Input Nilai Mahasiswa Sidang Tugas Akhir dan Skripsi pada Perguruan Tinggi . CSRID (Computer Science Research and Its Development Journal), 10(2), 113-125.

[10] Putri, E., Suryatiningsih., \& Muhammad, W. (2017). Aplikasi Pengolahan Data Anggota dan Informasi Kegiatan Taekwondo Indonesia Kota Cimahi Berbasis Web. eProceedings of Applied Science, 3 (3).

[11] Pamungkas, S., Prasetyaningrum, PT. (2018). Sistem Pendukung Keputusan Penilaian Ujian Kenaikan Tingkat Taekwondo Menggunakan Metode Weighted Product (WPFMADM). (Undergraduate Thesis, Universitas Mercu Buana Yogyakarta).

[12] Wibowo, A., Putra, A., Dewi, M., \& Radianto, D. (2019). Study Of Divergence Of Go Public Company's Financial Performance Based On Website Before and After Merger Using Window Period Method Time Frame 2015 - 2017. Aptisi Transactions On Technopreneurship (ATT), 1(1), 2751.

[13] Putra, A. I., Putra, A., Dewi, M., \& Radianto, D. (2019). Differences In Intrinsic Value With Stock Market Prices Using The Price Earning Ratio (Per) Approach As An Investment Decision Making Indicator (Case Study Of Manufacturing Companies In Indonesia Period 2016 - 2017). Aptisi Transactions On Technopreneurship (ATT), 1(1), 82-92.

[14] Dian, M. (2017). Rancang Bangun Sistem Informasi Administrasi Menggunakan Metode Throwaway Prototyping Development Pada Sultan-Sport.

[15] Sutrisno, S., \& Sajidin, A. (2019). Gadgetku.id application as a Solution to Facilitate the Fulfillment of All Gadget Needs today (case study: area Tangerang Banten). Aptisi Transactions On Technopreneurship (ATT), 1(1), 52-63. 